\title{
Theories of the Ground: The Sensitizing Theoretical Concepts
}

Having established the historical and structural context for Karl-Marx-Straße's contemporary daily life as well as for local businesses' survival, this chapter elaborates further on the underlying theoretical concepts that informed the selection process of certain businesses along Karl-Marx-Straße in order to explain why businesses are special sites for interaction and what kinds of interactions occur there. Subsequent chapters will explain the sampling of the specific types of businesses that constitute social life in Berlin-Neukölln.

This study works with a Grounded Theory Method Approach (GTM) (Glaser/ Strauss 1967 [German translation 1998]). Although a detailed discussion of this methodology appears in Chapter 4, it is important here to focus on an understanding of sensitizing concepts and their use in elaborating the iterative and cyclical process model of Grounded Theory Method here. GTM weaves together data collection, its analysis, the sensitizing theoretical concepts and the emerging theory. Crucial to this process are the initial data selection procedures that are particular to GTM: Neither principles of representativeness, nor the paradigmatic position of the data to be collected, nor its uniqueness are important. Rather, data is selected on the basis of analytical questions raised by the respective state of research and the state of theory formation - thus the term theoretical sampling (cf. Strübing 2008: 30). This process is defined as follows by Glaser and Strauss (1998: 53): 
Theoretical sampling means the process of data collection that is aimed towards the generation of theory, during which the researcher parallel collects, codes and analyzes her data, and decides what data should be collected next and where to find them. This process of data collection is controlled by the nascent - material or formal - theory.

As such, the observation positions and interview partners were chosen on the basis of "sensitizing concepts"80 (as theoretical and practical knowledge), whereby the selection criteria change according to the state of theory formation over the course of the research process, whereby turning ever more specific.

The sensitizing concepts themselves are deployed as interpretive devices, as starting points for the qualitative study, as markers of the important features of social interaction as practices, as guidelines for research in specific settings, and also as indicators for the selection of the cases themselves.

A literature review of potentially relevant concepts was undertaken before entering the field. It seemed appropriate not to follow Strauss and Glaser's suggestion to enter the field without having previous scientific knowledge on the research subject, because theoretical specification helped frame the selection of businesses to be studied and provided structure for the interview questions and participant observation. Further concepts were added with every new theme that developed out of the empirically generated data.

For the selection of appropriate sensitizing concepts (before and during the data generation and analysis process), the relationship between the sensitizing concepts and the theoretical sampling process deserves increased attention (the sampling process is discussed in detail in Chapter 4.1.): At the beginning of the research process, a first case is selected on the basis of the first sensitizing concepts (see Chapter 3.1., "public characters" and "third places"), which are supposed to reveal first tentative questions and possible perspectives on the phenomena under investigation. Successively more criteria for additional data selection evolve from the respective theoretical and conceptual conclusions of the existing material (Strübing 2008: 31; Blumer 1954; Bowen 2006: 2 f.). This deliberate selection of interviewees and observation spaces is accomplished by means of theoretical criteria derived from the sensitizing concepts, whereby no attention is paid to representativeness,

80 "A definitive concept refers precisely to what is common to a class of objects, by the aid of a clear definition in terms of attributes or fixed bench marks [...] A sensitizing concept lacks such specification of attributes or bench marks and consequently it does not enable the user to move directly to the instance and its relevant content. Instead, it gives the user a general sense of reference and guidance in approaching empirical instances. Whereas definitive concepts provide prescriptions of what to see, sensitizing concepts merely suggest directions along which to look" (Blumer 1954: 7). 
but rather to the respective types and structures. Consequently and gradually, the research project's sample is thus formed on the basis of the initial analysis on the one hand and the search for further theoretical insights through additional expected data sets on the other hand.

In short, the general question in theoretical sampling is: Which people, events, and social practices should be investigated further during the data collection and to what end? In this process, data collection and analysis of maximum contrastive categories (e.g. varying store sizes or 'hang-out' qualities, self-service, need of consultation, etc.) expands to include more minimum contrast situations (e.g. same type of business, of salespeople, etc.). In particular, by including extreme or dissimilar case, the theory consolidates and becomes richer and more multi-faceted (Flick 1995: 443).

Ultimately, three sets of sensitizing concepts in this study formed the conceptual framework, linking the various concepts and functions as an impetus for theory formulation.

The first set (which also sparked the search for an initial research question and inspired the entire research process in anticipation of entering the field site), was Jane Jacob's concept of a "public character" (1961: 68). A public character is understood as a neighborhood figure, who keeps their street safe and supports local social life and cohesion. An underlying research interest was to verify if these somewhat romantically described figures do exist on an urban neighborhood level and what makes such an individual a public character today. The second sensitizing concept that was examined and operationalized before fieldwork began was Raymond Oldenburg's concept of a "third place" (with Brissett 1982; 1989; 1999; 2001), a highly sociable place beyond the boundaries of the "first" (home) and "second" (work) places. In particular, his concept informed the research on the social practices that make a business sociable and in particular, on the businesses' material features.

The second and third sets of sensitizing concepts developed more in the course of the intertwined processes of data generation, data analysis, and the generation of increasingly more dense and solidified theoretical concepts. These latter concepts were derived through an extensive literature review centering on specific themes, such as sense of belonging and community building, public as well as neighborly interaction and behavior, the role of businesses and their owners for local social life, public spaces and urban retail development, shopping and consumption patterns, and the sociability of semi-public spaces. This reviewed literature along with the themes which emerged from the interviews and observations brought about my major argument that store owners' everyday practices in the course of their business operations contribute to community building and senses of belonging, and becoming socially significant places for some of the users. As such, a methodological focus emerged over the course of data collection that emphasized particular 
conceptualizations that consider community building and sense of belonging, but also neighborly interaction and public sociability as something that is practiced in the course of daily life, and thus underpin how neighborhood social life unfolds. Applied to independent retailers and gastronomic facilities, the nexus among these theoretical concepts is examined not only for the evolving sampling process, but also as the theoretical backbone of the whole research process. Put together, the conceptual framework for the study included three sets of sensitizing concepts, sense of community/ belonging, public interaction and third places/public characters, all of which provide the analytic frame, serving as points of reference and as guides in the data analysis (Bowen 2006: 3 f.).

\subsection{Sensitizing Concepts I: Third Place and Public Character}

This is a study of sociability on the very local micro-level - respectively the (semi-) public places where sociability, mainly among neighborhood residents, is generated. According to Georg Simmel, all forms of association comprise sociability, but pure sociability is the play-form of association, the opposite of purposeful association. The sphere of pure sociability might seem as an artificial world cut off from the real matters of life, and indeed Simmel describes pure sociability as a superficial world, offering a "flight from life". Yet, the world of sociability is highly attractive, for in it "we construct and experience the meaning and force of [life's] deepest reality but without the reality itself" (Simmel 1949: 261). So as per Georg Simmel, sociability is

a distinct social form that distills out of the realities of social life the pure essence of association, of the associative process as a value and a satisfaction [...] Sociability extracts the serious substance of life leaving only "togetherness," the sheer pleasure of the company of others. [...] Freed of connection with the serious contents of life, sociability is truly a social game, and end in itself. (Simmel [1911] 1949: 255)

In sociability, the form can become disconnected from content: people talk simply for the sake of talking and yet these interactions are socially meaningful and highly important for the individual's well-being. Extending Georg Simmel's work on sociability, Raymond Oldenburg $(1989 ; 1999 ; 2001)$ analyzes the places in which sociable associations tend to take place. He calls one group of these social settings "third places" and defines them as, "a generic designation for a great variety of public places that host the regular, voluntary, informal, and happily anticipated gatherings of individuals beyond the realms of home and work" (Oldenburg 1989: 16). 
For my research, the concept of the third place (Oldenburg 1989; 1999; 2001, and Oldenburg/Brissett 1982) was used primarily to generate early assumptions about the kind of places that might engender higher levels of sociability among only very categorically known (Bahrdt 1969) or completely unknown people on a neighborhood level, to develop observational categories and to inform the empirical research into the businesses themselves.

Therefore, third place attributes served as an important variable in the sampling process, contrasted against businesses that are also not delineated in Oldenburg's work (focusing on bars). Although Oldenburg rarely conceptualizes the role of store owners, or of bartenders and other employees, here too his concept helps to distinguish the different sets of practices that generate sociability and sociality in businesses.

For the carriers of these social practices (and as such, the actors of this study), Jane Jacobs' idea of "public characters" (1961: 68) is also used as part of this first sensitizing concept on the specific features of the places - the businesses - and their legal owners. Furthermore, Jane Jacobs' book "The Death and Life of Great American Cities" (1961) inspired and still informs the whole research project: Her understanding of "public characters" (1961: 68) and "eyes upon the street" (1961: 45) are examined in detail in Chapter 7 , which discusses my findings on the role of store owners on Karl-Marx-Straße. While I am aware of her very nostalgic and normative ideas of what neighborhoods and sidewalk life are supposed to look like, and that her work is based on her own personal (instead of scientifically systematic) observations and public interactions in her neighborhood of Greenwich Village in New York in the 1960s, this critique does not take away from her analytical insights. Similarly, her idea of the public character, which emerged from her own interactions with and observations of the store owners in her neighborhood, carries a continued validity despite its nostalgic aura. Her reoccurring description of them (e.g. the butcher or the superintendent) emphasizes that they do not only watch out for the streets and their sidewalk lives, but also take over little services, including key exchanges or the care of local children. These public characters with their manifold roles for the neighborhood could also be counted on to, for instance, let the parents know if their children were getting out of hand on the street, or to call the police if an odd stranger was hanging around for too long: "Storekeepers and other small businessmen are typically strong proponents of peace and order," Jacobs explained, "they hate broken windows and holdups." As per Mitch Duneier (1999: 6), she also modeled these public figures after persons like herself, who distributed petitions on local political issues to neighborhood stores, spreading local news in the process. However Jacobs (1961: 68) did not fully define her concept: 
A public character is anyone who is [...] sufficiently interested to make himself a public character. [...] His main qualification is that he is public, that he talks to a lot of different people. In this way, news travels that is of sidewalk interest. Most public sidewalk characters are steadily stationed in public places. They are storekeepers or barkeepers or the like. These are the basic public characters.

On this somewhat vague definition she also bases her observation that all other public characters on the street, as well as the social structure of the street as a whole, "hang partly" on these public characters, insofar as "the social context of the sidewalk is patterned in a particular way because of the presence of the public character: his or her actions have the effect of making street life safer, stabler, and more predictable." (Duneier 1999: 6) As per Jacobs, this occurs because the public characters have "eyes upon the street" and take care of what happens outside of their businesses (Jacobs 1961).

Certainly, Jacobs' early 1960s Greenwich Village (Hudson Street specifically) does not share many commonalities with $21^{\text {st }}$ century Karl-Marx-Straße in terms of the residential and commercial structures, municipal building, but also shopping and mobility patterns, and business operations and so forth. Nonetheless, her work on public characters is fundamental to our understanding of the sidewalk as the sites where the practices of particular actors - namely storekeepers - develop a sense of mutual support and familiarity among the more or less acquainted people who populate them. Furthermore, Jacobs emphasizes the role of mutual respect for the creation of appropriate limits on interaction and intimacy in the production of that social contact - even if this is something that cannot be taken for granted on a highly diverse shopping street in the $21^{\text {st }}$ century (Duneier 1999: 7). ${ }^{81}$

Beyond the notion of "public characters," I also draw on Raymond Oldenburg's ideas of public sociability $(1989,1999,2001$, Oldenburg/ Brissett 1982) that he defines through a detailed account of the kinds of interaction that happen in "neighborhood places" (Oldenburg 1997: 9). While my research is rooted in his original ideas on public sociability, I would argue that that a much broader range of businesses, from small neighborhood shops to occasionally even corporate chain stores, franchises, and shopping malls, can (and do) function as places of sociability for customers - depending on the physical attributes of the place, and the social practices of its owners, employees and customers. Furthermore, Oldenburg's work lacks a precise empirical analysis of his assumptions on third places and their important function for the social cohesion of US American cities, including the question of scale of the

81 See Chapter 7 for more information on the definition of the concept as well as on the concrete sets of social practices that make a store owner a public character. 
places under discussion (are they blocks, neighborhoods, villages, towns, cities?) - a lacuna that this present research intends to correct. ${ }^{82}$

Oldenburg's work builds upon the $19^{\text {th }}$ century theorist/ sociologist/ thinker Ferdinand Tönnies' (1887) concepts of Gemeinschaft and Gesellschaft which he used to describe the types of interpersonal relationships and networks created in a rapidly industrializing and urbanizing society - the former as a real, organic, and specifically private social formation; the latter as a mechanical, ideal, and specifically public social formation (Tönnies 1987: 4). Tönnies’ main concern was the loss of community as "Gemeinschaft" in larger industrializing cities, where residents live under the threat of losing their identity, intimate relationships and emotional support, due to a lack of both informal and formal gathering points. Expanding on Tönnies' work, Oldenburg suggests that people require informal public places (outside the bounds of home or work places) where they can regularly go to for the sake of relaxation and conversation, in order to remain "healthy" as well as to maintain their sense of Gemeinschaft. He defines these (semi-) public places of sociability as third places, "public place[s] that host[s] the regular, voluntary, informal, and happily anticipated gatherings of individuals beyond the realms of home and work" (Oldenburg 1999: 16).

For Oldenburg, third places are essential places in urban dwellers' lives along with their first place (home) and their second places (work). While all three are important for conviviality, a more homogeneous and more selective sociability exists, is created or engendered in the first and second places. These cafés, bars and shops as semi-public spaces bring about and hold together communities. They are the places that function as a substitute to the traditional historical urban market place - the social settings that encourage regular, but not necessarily trivial, interaction between customers, where urban residents spend their leisure time, while simultaneously providing them with food, drink, or the goods and services needed to supply their homes. What makes third places and the community formations therein so special is that there are no mutual obligations between the visitors - they come and go (and purchase or consume) as they please, which allows for a greater

82 Oldenburg focuses mainly on bars and restaurants in his elaborations of the sociability and sociality of third places, although he originally also included other semi-public and public spaces such as main streets or libraries: "The tavern, the bar, is without doubt the dominant third place in our society and we are not unique in this. Be it the saloon, cocktail lounge, pub [...] - the bar is nonetheless at the core of the institution (Oldenburg/ Brissett 1982: 269). By contrast, I include businesses of daily supply or daily services in my analysis, since they also function as third places and display third place characteristics. 
sense of relaxation and relief than in first or second places, where people expect each other to act according to their respective roles (Oldenburg 1999).

Railing against shopping malls, which he also calls non-places, Oldenburg embodies a nostalgic and intellectually conservative standpoint, praising little shops for functioning as community information centers, providing homeliness and comfortable sensual experiences (Mikunda 2004: 5) - alongside the goods for sale. For him, socializing and the search for Gemeinschaft or community is thus of primary interest to people coming to these places - and thus the primary activity. Paralleling Robert Putnam's critique of the loss of social capital in "Bowling alone" (1995; 2000), Oldenburg (in his early work with Dennis Brissett) laments the steady decline in people's sense of responsibility and control, caused by the narrowing range of available arenas for social participation to the two-stop-model between home and work place (Oldenburg/ Brissett 1982: 265 f.). The authors further bemoan that the neglect by scholars and planners alike of the role of third places in creating a sense of community, has further decreased the opportunities for congregation outside of first and second places. Fundamentally, the main problem of the American society is the loss of specific spaces where people can interact without the pressures and expectations typical for social interactions at home or at work. As such third places act as "get-aways" or a "home away from home." Moreover, they argue that if these facilities and public spaces are endangered, and urban environments become incapable of providing opportunities for social relationships and diverse social experiences, the overall social fabric of a neighborhood or society is endangered as well (Oldenburg/ Brissett 1982: 267; Oldenburg 2002).

Emerging out of their predecessors - German beer gardens, English pubs, French cafés, and village or town market places - these third places are free or inexpensive establishments, often serving food and drinks, and highly accessible for most of their visitors, and who frequented these places on a regular and habitual basis. Further, third places provide a welcoming and comfortable atmosphere, making it easy to congregate there, make new friends meet old ones. These places provide a home away from home, without the constraints and role expectations as to be found in places of work and residence, resulting in a quite playful mood. Nonetheless, customers most often only know each other casually in their role as acquaintances in a bar or restaurant.

But Oldenburg does not go into a definition of home or community or how the two are perceived and practiced by staff or customers themselves. His thoughts remain very superficial and based mainly on the observed conversations in, and a historical literature review of, selected third places. Furthermore, his sampling remains very unclear: the discussed examples are most often longstanding neighborhood taverns and diners with customers of different gender and age groups, 
but most often with the same ethnic and racial background. In addition, all his discussed facilities are family-owned and owner-operated places on or near main streets in American cities. Although Oldenburg is aware that key ingredients often remain elusive, emergent, or subject to shifting lifestyle patterns, he does ascribe rather narrowly defined characteristics to his model third places as places of public sociability (1999: $20 \mathrm{ff}$.):

Third places offer neutral ground, where visitors have little to no obligation to be there, none of them has to act as host or guest. In addition, customers are not committed to the place financially, politically, legally, or otherwise - they are free to come and go as they please. Further, third places place little to no importance on the visitors' social status. Their socio-economic background does not matter in these facilities in terms of permitting entrance, participation, or special attention by other actors in the location. Rather, participation and congregation in third places is based on a greater or lesser equality of all visitors with a sense of commonality for the length of the stay. These low expectations of customers often extend to the space as a whole - third places are characteristically "wholesome," with a homely feel and lacking pretentious or snobby salespeople and customers, but also extravagant and grandiose décor and attitude (Oldenburg/ Brissett 1982: 270).

My observations as well as other ethnographic studies on bars and coffee places contradict his utopian view: In practice, most dining and drinking facilities are structured by gender, class, and ethnicity. This happens most often in informal ways and often through self-selection; furthermore, some places actively select a particular type of clientele though door policies.

In situations of pure sociability, one enters, according to Georg Simmel (1949), into the most purely democratic experience life can offer, where people "are truly different but truly equal" (Oldenburg/ Brissett 1982: 271), since a person's status does not inherently matter in the maintenance of human fellowship. Yet, Oldenburg's ascribed characteristic of third places being a "leveler," setting no criteria for social inclusion, is rather utopian, since most businesses and particularly dining and drinking facilities are highly structure by gender, class, and ethnicity (cf. Share 2003: 11). Despite the "feminization" of many public places in the course of the $20^{\text {th }}$ century, bars and many nightlife facilities remain often highly masculine and thereby highly exclusionary places. His most prized of "leveling" third places, the neighborhood tavern, fundamentally excludes certain population groups by dint of the fact that alcohol is sold there. Today's metropolitan areas - such as the neighborhoods around Karl-Marx-Straße - have ethnically and religiously diverse populations, many of whom do not drink alcohol and do not visit places where alcohol is sold because of their beliefs or lifestyles. 
However, the core of Oldenburg's delineation of third places (and for him the most obvious of all opportunities within such places) is the possibility of pure sociability. Referring to Georg Simmel (1949: $254 \mathrm{ff}$.), this pure sociability goes beyond special and immediate purposes and brings people together. According to Simmel, people need this kind of pure sociability in addition to other forms of associations in the "outside world," defined as associations entrusted for a specific purpose, subordinated to the required roles and organizational criteria (Oldenburg/ Brissett 1982: 271). Third place sociability, by contrast, means fully playful, "humorous," and "happy" face-to-face conversations. These are the main activity, although topics can vary and getting more serious over time and also might be accompanied by other activities, such as drinking or eating together. He often defines the mood of places as determined by a playful conversational tone without serious tensions or hostilities (Oldenburg 1999: 31). But in his enthusiasm for the "great good neighborhood places," Oldenburg seemingly ignores the fact that talk can also be used as an instrument of oppression.

Another important feature of third places as places of sociability, according to Oldenburg, are the regulars themselves, who not only give the place its tone and contribute to the mood and verbal climate of the space, but also attract other customers and influence how other (first time or non-regular) customers perceive the space and its inclusivity. Ostensibly, it is not the surroundings or even the service that make a third place attractive, but the other customers, where the ultimate goal is to become a regular, and thus to develop a mutual relationship of trust. Here, Oldenburg does not go into the role of shopkeepers, bartenders, and other third place employees. For him, public sociability evolves rather as something natural among regular customers, not directed or fostered by any "formal" owners of the place. I, on the other hand, doubt that interaction among customers, no matter if related or not, develops without direct or indirect incentives from the employees (and owners), since they set, frame, and govern the behavioral and interactional rules for the places.

Another important attribute, as per Oldenburg, is a third place's easy access and accommodation by means of its (ideally) walkable location and physical design, including a décor, lighting, furniture, and its arrangement, as well as other artifacts such as play toys, newspapers, or bar games, all of which please and match with the needs and desires of its clientele. I argue that $t$ hese details do not appear sui generis, but are clearly crafted either purposefully or accidentally by store owners and employees. In that sense, it becomes clear that the impact and social practices of store owners and employees are much more important than originally argued by Oldenburg: They build, design, and decorate the place, they decide where to put up tables, combined with a specific lighting system, how to promote offers; they 
choose the kind of music and the volume at which it is played, and so on in order to order to generate an atmosphere and a design to fit their business ideals, concepts, profit expectations, and daily operations.

Oldenburg focuses on the spatial location rather than the interior physical qualities of third places. He decries American planning regulations that too often exclude such places from urban and suburban areas, and pleads for easy accessibility that requires a high number of third places across the cityscape and within residential settlements. Their quantity and presence do matter, but more so do Oldenburg's outlined benefits of third places: the provision of an atmosphere of familiarity, feelings of possession, belonging and intimacy, the constitution of a home away from home, but not far away from home. Even if close to home, the defining feature is that these places are not home, yet the atmosphere and feelings of homeliness affect how people move and behave in third places, in that they engage in practices such as taking off shoes, scratching themselves, or marking newspapers and discussing private issues without high levels of secrecy (Oldenburg/ Brissett 1982: $271 \mathrm{ff}$.). With Oldenburg, the underlying assumption for the current empirical inquiry is that businesses as everyday places receive an ever-shifting variety of locally resident and/ or working individuals and sometimes even "external" visitors, who are all granted participation by virtue of their co-presence in the course of routinized everyday life. In third places, people of different professions, milieus, and origins might end up next to each other; whereas at home or at work, interactions are not only highly regulated and standardized, but also occur mainly among people of very similar and selected backgrounds (Oldenburg/ Brissett 1982: 274 f.).

Further potential benefits of the participation in third places are, according to Oldenburg (1999), that people find emotional relaxation there, since they are freed from their role expectations and can thus express a higher level of emotion - but nevertheless dependent on the respective business' behavioral codes and corresponding atmosphere. Third places in Oldenburg's estimation are often very loud and lively places, where emotional conversations are common, where people discuss very private topics specifically because of the lack of strong ties between the customers. Revealing private issues just serves the purpose of personal release not available when discussing these issues with someone more related. This leads to another benefit of third places: perspective. As per Oldenburg, third places help to overcome social isolation and foster mutual support. Frequenting third places enlarges customers' social networks, but further, visitors to third places might end up sitting next to a plumber, who could be hired for a repair, or someone who rents out an apartment, someone who knows a good doctor or nanny. These relationships, even if confined to the length of stay in the business, might thus help to overcome situations of need (Oldenburg/ Brissett 1982: 280 f.). In addition, with 
this "incomplete integration" 83 (Bahrdt 1969: 86) or the only partial knowledge of others in the place, third places provide a responsive arena for the individual reality construction for each customer. According to Oldenburg, a healthy measure of role distance becomes important in the retention of mental perspective (Oldenburg/ Brissett 1982: 282).

Having characterized the main features of third places, Oldenburg admits that mere participation in third places does not guarantee "anything," which I interpret as no guarantee of sociability or of personal happiness. Certainly, he and Brissett see many positive elements in third places, such as the discussed sociability, leveling, and community building. However, they consider the positive consequences as emergent and rarely linear, while providing users access to social experiences and relationships that are increasingly unavailable outside these places in society at large (Oldenburg/ Brissett 1982: 273). It also remains unclear if membership in these places extends to the "outside" world, if customers maintain and sustain their third place acquaintanceships or friendships outside of the businesses in question, and as such, if the sociability of third places actually leads to higher integration and participation in broader society. ${ }^{84}$

Another critique concerns the increased self-marketing of businesses as third places, which erases the commercial aspect inherent in running a business by making it disappear behind a mask of sociability. For instance, the Starbucks Corporation actively promotes its chain coffee stores as third places, pretending that the sociability - the warm and welcoming atmosphere of these cafés - matter more to the company and its employees than selling pricy coffee and baked goods..$^{85}$ Starbucks

83 As per Hans Paul Bahrdt, incomplete integration means that only one aspect of the personality is introduced in the respective interaction, while other aspects are ignored or hidden. By participating in the 'market' (as the central urban space), a person is integrated in a system of exchange, but this integration is not aimed at the whole person, wherewith Bahrdt calls this integration incomplete (Bahrdt 1969: 86 f.).

84 For these questions it becomes obvious that Oldenburg's conceptualization lacks empirical data and evidence.

85 See Mikunda 2004: 5; Starbucks (n.d.): "Your Starbucks experience is so much more than just coffees. It's the conversation you have with a friend, a moment of solitude at the end of the day, a quick stop on the way to the movies. And in the tradition of the coffeehouse, it's also the chance to immerse yourself in eclectic and enduring music while you sip your favorite coffee" (Starbucks (n.d.). Our Heritage, http://www.starbucks.com/about-us/our-heritage, accessed 04/20/2015). Dave Olsen, Vice president of Starbucks also wrote in the introduction of "Starbucks passion for coffee: A Starbucks coffee cookbook (Sunset Books 1994: 8)": "Today, as they first did more than 700 years ago, coffeehouses offer a delightful diversity of experiences. You can chat with friends, join in heated discussions or read in solitude. You can study, sketch or write. You can 
advertise their third places as "safe," "comfortable," and "nonthreatening," referring to the same discourse of homogeneity and notions of safety and comfort that find their material expression in highly segregated and gated residential communities, as well as in the widespread deployment of police, security guards, and electronic surveillance systems in malls, parks, and other public settings. Starbucks did not begin to promote their stores as third places until the mid-1990s, when they began to capitalize on the social and interactional desires of their overworked middle-class customers with a nostalgic narrative of "community life" (Gaudio 2003: 678). Similarly, other dining and drinking institutions also see an opportunity to capitalize on the concept of third places by marketing themselves as such or even by making it an essential part of their brand (Crick 2011: $2 \mathrm{ff}$.). The function of retailers and dining facilities is - of course - first and foremost to sell and create profit. Since third places represent a seductive experience, they often draw on these "third place experiences" in order to increase attention levels, length of stay, and subsequently their sales. Through "mood management" or "convenience entertainment," emotions become a value-added in the consumption experience, linking "true, big feelings" to the shopping environment, the salespeople, or the products sold (Mikunda 2004: 6 ff.). I am highly aware that the small businesses' owners and salespeople along Karl-Marx-Straße might also use such techniques to bind customers to their business, increasing the length of their stay and the number of goods purchased, as a means of pro-actively defending against the competition, while increasing their own profitability. In a nutshell, generating a third place and sociability becomes a concrete business strategy.

Despite the danger of being capitalized or turned to account, Oldenburg's concept of (semi-) public places that are used as private habitats, draws attention to the previous and ongoing restrictions on spheres available to urban residents for social participation. These restrictions are mostly due to structural changes, longer working hours, as well as a turn to the more exclusive sphere of family during the scant leisure time. Both work and home places are highly predictable and homogeneous in terms of ethnicity and lifestyle. Third places, by contrast, expose their visitors to diversity and novelty, and thereby represent fertile ground for practicing the $21^{\text {st }}$ century diverse metropolis (cf. Chapters 1 and 2).

Building from Oldenburg's notions of neighborhood places and Jacobs' ideas about neighborhood figures, my research expands the line of inquiry to investigate

listen to music or hear poetry recited. You can play cards, checkers, backgammon, chess. As an unsung Viennese wit once put it, a coffeehouse is 'the ideal place for people who want to be alone but need company for it.' All the while, whatever you choose to do, you can sip and enjoy one of the world's great pleasures." 
how the physical design of the stores alongside the social practices of the store owners and other staff, coupled with the often unknown yet repeating mixes of people that share the space at a particular time, are responsible for a more inclusive or exclusive, good-spirited or strict, familiar or new atmosphere that supports (or does not) the generation of a sense of community, home, or belonging.

Hence, these are the main assumptions derived from third places and public characters as the first set of sensitizing concepts, which subsequently informed the empirical inquiry into Karl-Marx-Straße. While Oldenburg's third places encourages interaction and familiarity among all its participants, the sampled businesses and their owners might foster interaction for only some or none of their customers, some businesses might not have a regular or already acquainted clientele at all. Nonetheless, just as Jacobs' public character idea polishes the analytical lens for the social practices of store owners, I chose Oldenburg's third place model because it reveals the potential for discovering the relatively uninhibited sociability among mainly unacquainted others - sometimes strangers - in (semi-) public spaces.

Some of the operational research questions seek to expand on Jacobs and Oldenburg's models: first, in order to include other - non-gastronomic businesses - as the most visited places of everyday supply, and second, to include the role of the individuals working in these businesses. Are they aware of the 'third place functions' the business fulfills, do they practice third place intentionally, and why? How do businesses and their staff affect customer interaction? How does the respective physical design of the businesses represent, prevent, or support third place 'qualities'? If Karl-Marx-Straße's businesses are indeed a type of third place, for whom are they so? What role do these businesses as third places play for the neighborhood and broader society?

Within this context, I considered size, type, accessibility and location, as well as customer mix (especially the presence of regulars), and the overall atmosphere and mood in the businesses as variables in the course of my theoretical sampling process. Since visitors can never fully predict the social mix and atmosphere of a third place, due to variable factors such as the time of day and week, other potential customers and their moods, and furthermore because strong ties do not seem to be the dominant type of relationship in these semi-public places, the benefits of third places depend strongly on particular time-space settings. I thus presumed in this research that much interaction takes place between more or less acquainted individuals and even complete strangers. Their only commonalities might be their place of residence in the vicinity of the respective business and their co-presence therein during a specific time of the day and week. Hence, most interaction in these - third or not - business places is first, interaction in (semi-) public space and thus second, interaction among "strangers." 


\subsection{Sensitizing Concepts II: Interaction in Semi-Public/ Public Spaces}

Karl-Marx-Straße, as a diverse metropolitan shopping street is, among other things, a "world of strangers" (Lofland 1972; 1973) and so are its businesses. These little worlds of strangers are populated by urban residents (but also visitors) who are likely unknown to one another (Lofland 1972; 1973). Since the businesses may work as contact sites for both strangers and already acquainted people, the second (set of) sensitizing concept(s) my research grows from the concept of interaction in semi-public and public spaces, which is analyzed by means of various analytical categories, including Lofland's scheme of private, parochial, and public spaces, as well as the notion of public life as theater.

As Lyn Lofland (1972) argues, sociology has mostly ignored the relationship among strangers and acquaintances. ${ }^{86}$ Whenever sociology addressed the general relationships among urban dwellers, the main focus has been on primary and secondary relationships - relationships in which the interacting individuals already know each other. This is likely to have produced the widespread sociological assumption that interactions among strangers in public spaces are not real or socially meaningful, and thus - cyclically - that these interactions and encounters were not of interest (Lofland 1972: 106).

Stemming from this lack of research on public space and the sociability therein, Lofland develops a new differentiation between the private, parochial, and public realms and their respective behavioral forms, in order to outline how widespread, common, and meaningful interactions between unrelated people or only categorically related (cf. Bahrdt 1969) people in urban settings are. The public realm as a social territory is "the unique social and psychological environment provided by urban settlements" (1998: xii), while public settings are those

regions in a community which, as Goffman (1963: 9) has said, are 'freely accessible to members of that community'. I refer to this part of urban world [...] as 'any street, alley, park, public building, any place which is open to public view or to which the public has access.' (Ann Arbor, Michigan Ordinance Code 1957: ch. 108, Paragraph 9: 61) (Lofland 1972: 107)

Yet, public settings do not necessarily belong to what she calls the public realm. The public realm is defined as the non-private areas of urban settlements where

86 However, there are few exceptions, such as Georg Simmel's work also focuses on the relationship between an individual and to a group than between individual strangers themselves. 
individuals when present there tend to be strangers to one another or know each other only in terms of the relevant categories, such as in their professional role or in what they currently practice (Lofland 1989: 454). From this follows that the businesses along Karl-Marx-Straße - as Lofland would describe them - are parts of the parochial realm, even if they consist of public spaces and places. Lofland's categorization of certain spaces as public, parochial or private stems from the types of relationships and behavior that are to be found in those locations.

In this research, I follow her conceptualization and consider the studied commercial facilities as public or semi-public spaces, which, according to the observed forms of behavior and ties, are then sub-categorized as either public, parochial, or even private realms.

\begin{tabular}{|l|l|l|}
\hline & Public Realm & Parochial Realm \\
\hline Locale $^{87}$ & City Center Plaza & $\begin{array}{l}\text { Newly Trendy Ethnic Restaurant in a Stable } \\
\text { Neighborhood }\end{array}$ \\
\hline Location & $\begin{array}{l}\text { Private Home, Territory Bar in } \\
\text { City Center }\end{array}$ & Neighborhood Bar \\
\hline
\end{tabular}

Fig. 14 Chart on public and parochial realms, derived from Lyn Lofland's original ${ }^{88}$

It must be noted that the "lines" between these categories are often blurred by the everyday practices of salespeople and customers alike, who, depending on their personality, mood, relationship with other people present, their perception and sense of ownership or belonging of the place and the like, constantly switch between the respective behaviors. As such, a clear assignment of the interactions in the businesses to each of Lofland's categories becomes difficult. But Lofland also describes all "real" places as existing in a continuum between private and public, private and parochial and between parochial and public. In non-private spaces, people may only be known to each other by the categories they visually present as (race, gender, religion); but life in public spaces is nonetheless thoroughly social (Lofland 1989: 457). This might seem to contradict Oldenburg's elaborations on the

87 "A locale is where people with similar values and identities are likely to be found" or bounded portions of non-private space in which people are likely to be similar. By contrast, a locale is a place or "street that draws to itself different sorts of populations" as a space in which people are likely to be strangers, or dissimilar or only categorically known to each other (Lofland 1989: 456).

88 Source: Lofland, 1989: p. 456. 
intimacy of third places, displaying closely-knit relationships between customers, but must be understood as a continuum in reality, where these places also facilitate the integration of new and unknown visitors into the familial setting. Hence, the second theoretical starting point for the examination of sociability in businesses along Karl-Marx-Straße is interaction with (eventually) unknown others - in settings that are "public" or open to the public, but not necessarily used as public places.

In the development of my early assumptions and observational categories for the empirical field work, this research also drew upon the work of Erving Goffman $(1963 ; 1971)$ as a means of studying this continuum of social interaction (as social practices) in public places, as well as of the (semi-) public spaces themselves, and to help conceptualize these interactional types of behavior. According to Goffman, the fundamental characteristics of interactions between more or less known individuals in public settings are a complex production of social order, the gradual integration of individuals and their practices into a pattern of mutually understood cooperation, such as "techniques that pedestrians employ in order to avoid bumping into one another. These seem of little significance. However, they are constantly in use and they cast a pattern of/in street behavior." (Goffman 1971: 6) The crucial question for the study of interactions within individual businesses is then how this order emerges and how participants consensually interact without irritations. ${ }^{89}$ In order to conceptualize these interactions (and other meaningful social practices) among widely unacquainted people in such public settings, Lofland's work (following Goffman) also helps in our understanding of social life in public spaces (just as in all societal spaces) as both following specific rules, and depending on human relationships.

These rules represent a set of "techniques-tactics" with which people can cope with strangers (Lofland 1972: 94; 1989). They need these techniques or rules in order to maintain their self-esteem, to protect and guide themselves, competently through these public settings (Lofland 1972: 95). The three main principles are civil inattention (in reference to Goffman 1963), audience role prominence, and civility towards diversity (Lofland 1989: 461). Goffman (1963: 83 f.) conceptualized civil inattention as follows:

When persons are mutually present and not involved together in conversation or other focused interaction, it is possible for one person to stare openly and fixedly at others, gleaning what he can about them while frankly expressing on his face his response to what he sees - for example, the 'hate stare' that a Southern white sometimes gratuitously gives to Negroes walking past him. It is also possible for one person

89 The only commonality among people in public spaces, such as in some of the businesses along Karl-Marx-Straße, might be that they occupy the same territory at the same time. 
to treat others as if they were not there at all, as objects not worthy of a glance, let alone close scrutiny. Moreover, it is possible for the individual by his staring or 'not seeing' to alter his own appearance hardly at all in consequence of the presence of the others. Here we have 'nonperson' treatment, it may be seen in our society in the way we sometimes treat children, servants, Negroes, and mental patients.

Currently in our society, this kind of treatment is to be contrasted with the kind generally felt to be more proper in most situations, which will here be called 'civil inattention'. What seems to be involved is that one gives to another enough visual notice to demonstrate that one appreciates that the other is present (and that one admits openly to having seen him), while at the next moment withdrawing one's attention from him so as to express that he does not constitute a target of special curiosity or design.

As per Lofland (1989: 402), whether or not civil inattention is exactly as Goffman describes it, there can be no question about the existence and power of this first rule of public behavior: "It is, perhaps, the absolute sine qua non of city life," (Lofland 1989: 402) and as such we become aware of it only in case of interruptions, exceptions, and variations - for instance, if people stare at each other in the subway or if someone intrudes on another's privacy by getting too close.

Civil inattention is the first form of "cooperative motility" (Lofland 1998: 29) and does not imply complete inattention. The less public a place is perceived and practiced, the more friendly people recognize each other. For instance, on a neighborhood level or within neighborhood stores, people greet each other, by a friendly nod, a short greeting, often including the other person's name and questions about their well-being, whereas in the "real" public, people instead perform civil inattention by avoiding body contact and/or excessively friendly or attentive looks into the other person's eyes. Even though Lofland ascribes neighborhoods and neighborhood places to the parochial realm, I argue that public behavior and therewith civil inattention, audience role prominence, and civility towards diversity are practiced in semi-public or parochial places as well, depending on, among many other factors, the sense of ownership, belonging, and familiarity with the place and other co-present people. However, all behavior in the public and parochial or semi-public realms takes place in a specific setting, and consequently adapts to it.

The second rule, audience role prominence, notes that all public behavior takes place with the awareness that there is an audience - other people present in the space. Lofland derives this rule from Goffman's work on public life as theater life, in which the front stage equates to the public and the back stage symbolizes the more private spaces. Working from this metaphor, the individual person acts in public as an actor does, always aware of his or her audience, relaxing and "performing" less as soon as he or she leaves to a more private space - the back stage. How many theatrical performances are available for the voyeuristic pleasure of the audience 
depends on the type of settlement, the social setting and time - ranging from love and fight scenes, nurturing babies or body care, to commercial and sexual exchanges - creating a "public ballet" where the dancers walk, sit, sleep, read, make oneself up, hug or watch each other (Lofland 1989: 263 f.). Restrained helpfulness or so-called public aid also stem from audience role prominence: being aware of the other people present, one can reasonably expect small favors from them, such as telling the time, opening a door, or asking for directions. The more parochial and less public the place, the higher degree of helpfulness is expected and exercised. For instance, on a neighborhood scale, or within local businesses, parochial aid ranges from small services such as accepting personal deliveries, transferring goods from one customer to another, taking care of pets, plants, keys, or even children for a limited time (Kusenbach 2006: 291).

Public behavior is a balancing act: If the public realm seduces its participants into getting too involved in other people's affairs, audience role prominence supports the ignorance of each other's affairs. The more parochial or private the realm is, the more attention or proactive care is desired and expected of other people against potential threats or discomforts (Kusenbach 2006: 294). Here, proactive intervention means extended helpfulness in contrast to public aid. The more proactive the intervention, the more people watch out for one another, the less public the place used is. For instance, in a local grocery store, people might secretly gaze into other people's shopping bag, but commenting on the chosen goods or their quality would be an intervention that exceeds the rule of audience role prominence for public settings - but is nonetheless a common interaction in many neighborhood businesses.

Lofland's last principle for public settings, civility towards diversity, refers to faceto-face interactions between very different people in a public space. Confronted with people of different ethnic and social backgrounds, with different styles, demeanor, and sexual preference, "urbanites", as per Lofland (1989: 464) (most often) act decently vis-à-vis this diversity in public spaces. However, this rule of urban public behavior does not necessarily mean that this kind of civility is inherently nice or polite. Referring back to Georg Simmel (1903), who similarly described urban residents as distanced, indifferent, and even blasé in order to handle the coexisting and loaded interactions in urban settings, Lofland argues that this civility towards diversity is actually indifference without mutual appreciation. However in semi-public or more parochial settings, participants rarely express complete indifference towards other people's differences, or conversely, the level of indifference that is expressed depends on the particular situation, practices, and people involved. Difference might be praised and welcomed in some situations; while in others, it is experienced as a threat. At different junctures, complete ignorance might be a suitable response, whereas at different times, only full inclusion and attention would be considered 
as appropriate (Kusenbach 2006: 297). In local retail and gastronomic facilities, much of this civility is thus determined by the owners' or salespeople's practices, allowing for membership in the place or not, setting the boundaries for tolerance, attentiveness and appreciation. In cases of conflict, deviant behaviors or attributes might cancel all membership rights; or, they might increase the sociability and inclusion of the place. Put together, these normative, implicit, and explicit rules of indifference along with audience role prominence, (including restrained helpfulness as public aid) and civil inattention guide individuals' behavioral conduct, avoiding chaos and dissonance, and finding different expressions depending on the degree of perceived publicness (Lofland 1989).

Along with the three principles of public behavior, the second ingredient in Lofland's conceptualization is that of human relationships. Public space can only be thoroughly social if its participants relate to each other. As an explanation for the (self-managing) behavior in public realms or settings itself, Lofland (972: $99 \mathrm{ff}$.) further offers a more detailed insight into how all public space users try to protect their rather fragile selves by employing a variety of survival skills, which generally results in a peaceful coexistence in public. By reducing or even avoiding their involvement with others, they support the existing social order. The management of the self follows specific sequences of approaching these public settings, but also the development of specific styles to cope with them. Lofland thus distinguishes three types of relationships that are most common for public spaces: fleeting, segmental and unpersonal/bounded relationships (Lofland 1989: 466).

Fleeting relationships have only a very brief duration and generally do not involve a spoken exchange beyond that of an inquiry/reply. This type of relationship is the most representative association form in the public realm and micro-manages the encounter of large numbers of strangers. However, fleeting relationships are continually transformed into more sociable forms: For example, a daily morning nod in the bakery may lead to a more personal conversation about daily schedules and so on (Lofland 1989: 466 f.). In my research, I assume that most contact building in businesses was of this fleeting kind, which occasionally develops into more committed relationships, even if only for the time of the stay in the business.

The term segmental relationships refers to relationships between people who only know each other in regard to limited segments of the self, such as by an occupational role. For instance, customer/salespeople interactions typically consist of segmental relationships. Other emotional aspects or segments of themselves are left out and are not necessarily relevant during the course of a usually short-lived interaction. This is also what Lofland addresses when she talks about categorically known people in public or parochial spaces - the people only know each other in terms of the relevant categories, such as in their professional role or in what they 
currently practice. However these segmental relationships can also easily develop into more personal relationships, when more emotional and biographical elements are integrated or interactions between the same segmentally know people repeat or take place on a regular basis (Lofland 1989: 467 f.). I therefore consider segmental relationships as particularly important for the conceptualization of customer-salespeople relationships, and of interactions where individuals begin to interact exactly because of a partial knowledge or recognition of a certain attribute in the businesses (for example, wearing a uniform, pushing a stroller, using a walking cane).

The third type of relationships that is common in public spaces is unpersonal ${ }^{90} /$ bounded relationships, which are neither intimate, nor fleeting, nor segmental. These relationships are simultaneously characterized by closeness and social distance, in which personal information is shared, but with the understanding that no relational intimacy is implied. These impersonal relationships are friendly and sociable, but do not necessarily leak over into the private or parochial realms (Lofland 1989: 469). For Lofland, typical examples of such relationships are customer interactions in dining or drinking facilities, laundromats, or clothing retailers. For the local businesses along Karl-Marx-Straße, I consider unpersonal/bounded relationships as necessarily constituent in the maintenance of the local social order and relaxed atmosphere, and concerning the business people, as a common interactional practice to smooth business operations or even increase revenues and customer loyalty.

Lofland's ideal-typical differentiations of behavior and relationships serve in this project to highlight where, how, and under what conditions meaningful interactions and relationships between people in (semi-) public spaces can occur. Depending on the respective relational type, the space can then be distinguished as a more publicly or privately used space as part of Lofland's scheme of public, parochial, or private realms. The relationships themselves change constantly: fleeting relationships become unpersonal/ bounded, and vice versa, home spaces disintegrate, whereas segmental relationships might begin to involve sentiment and so forth (Lofland 1989: 470). This applies in particular to spaces such as businesses, where formal ownership may be private, but which are open to the public, and thereby offering opportunities (and hidden corners) for more private behavior and intimate relationships, as well as for the (only fleeting or more committed) intercourse with complete strangers.

Lofland's detailed categories are particularly helpful for ethnographic observations of the customers in businesses and how they accommodate themselves in the respective public setting. For example, when an individual approaches a crowded setting made up predominantly of strangers, they cannot make an entrance un-

90 "Unpersonal" is the precise term Lofland uses (1989: 468). 
observed, since the other customers have already secured their positions in this setting and the salesperson is trained to pay attention to any newcomers. Hence, the entering person needs to observe and "if necessary, rearranges his [or her] body presentation to make certain nothing in his [or her] appearance will jar the image he [or she] wishes to convey." (Lofland 1972: 99) This is why most people take care of their outfit and hairstyle, and make last-minute adjustments to their presentation, before entering such settings. The business becomes a front stage setting, where these readiness checks are practiced within the view of at least a few strangers. They spend only a few seconds on this backstage behavior in order to be prepared for the front stage performance. When they enter the business, they take a reading of the setting in order to familiarize their selves with the space's physical layout and to avoid errors such as walking into walls or private rooms, stumbling over furniture or waiting at the wrong end of the line. Herein, the importance of self-management in the maintenance of a space's social order becomes clear. As per Lofland (1972: 101), the act of assessing a physical layout can demand different levels of attention, from taking off outdoor clothing or sunglasses, reaching for a cigarette, shivering or sighing, or just taking a look around, to - least intensively - avoiding any reading at all by blindly following other customers. The final step of approaching a public setting is to reach the final position: In my business cases this could be achieved by, for instance, securing a table, sitting down with the ordered goods at a chosen location, joining the cashier's line, stopping at the counter and so on. The more the participants have read the space, the more alternatives exist as to where to come to a halt. Securing a position within the space signals the beginning of a new phase in the individual self-management among strangers, in which the individuals are then able to take a more frank appraisal of the setting (Lofland 1972: $105 \mathrm{f}$.).

Most people one encounters on streets, in parks, in businesses, subway stations and so forth, are not personally knowable, but at least identifiable as representatives of a category (gender, employment, age, etc.). Armed with this information, one knows how to act toward these strangers: one can live as a stranger in the midst of strangers, since the gleaned knowledge dismantles some important elements of the strangeness (Lofland 1973: 15). Individuals gain this knowledge and ability to order strangers from their own experiences, and their socialization. This categorization of a stranger is based on observation - gaining partial information on their status or role from their utterances, physical appearances (body presentation, clothing, and hairstyle), and physical location. Lofland (1973: 27) calls the first appearential ordering and the second spatial ordering. These two principles of ordering help the individual, a stranger themselves, to behave competently among other strangers in public spaces. 
As the knowledge of a particular space increases, so too does the familiarity of a space as well as its participants - which might eventually allow for such a setting to be used for private purposes as well. The more individuals develop knowledge of social categories, the less they perceive a place as strange or alien, and the more the space begins to seem like home for them. With a certain (high) level of knowledge, individuals then also behave as if they are in a private place, occupying, colonizing, and creating a home territory, but also developing attitudes of property in these nonetheless public spaces (Lofland 1973: $122 \mathrm{ff}$.). This corresponds to Oldenburg's idea of third places and the respective behavior: The ordering of the space and its participants enables private behavior and intimate interaction with nonetheless unknown people in a public space. ${ }^{91}$ The ability to categorize thus serves as a basis for action - for social practices that foster feelings of belonging and community.

Put together, these principles of public behavior, the types of public space-relationships, and the concept of self-management allow for a deeper understanding of the ways people interact in the public and semi-public spaces of businesses, and furthermore, how these businesses might be turned into more private spaces through distinct social practices by staff and/or customers alike. Ultimately, Lofland's and Goffman's work explains how city life, if we define it as living together with largely unacquainted strangers with the regular experience of anonymity, is enabled. Nonetheless, both authors insist that living in full anonymity would be intolerable. As such, the fine line between more or less personal relationships, even in its shortest and most fluid form, is crucial for the well-being of an individual in cities (Lofland 1973: x f.).

To turn directly to the topic at hand, this research applies Lofland's and Goffman's rules, categorizations, and behavioral principles as a second set of sensitizing concepts for my analysis of the privately owned (semi-) public spaces of businesses on Karl-Marx-Straße. On this very local level, shopping as well as consumption involves concrete and real interactions with other real human beings, constituting an important snippet of everyday social life. Following Lofland's and Goffman's elaborations on public behavior, in the moment of interaction of two or more involved people, they act according to these addressed rules and expected roles. For the local businesses along Karl-Marx-Straße, the roles that involve most of the interactional social practices are most likely those of customer and salesperson. Nevertheless an assumption derived from Lofland and Goffman's elaborations is that people in these businesses act in multiple roles and conduct different social

91 The type of knowledge and subsequent practices decide about how the space is perceived and practiced and thus these public spaces are often turned into semi-public or private settings. 
practices simultaneously. Hence, participation in these places requires different types of roles, and social practices, as well as rules and related their negotiations.

To conclude this subsection, the concept of public behavior and its modification for semi-public or parochial spaces as the second set of sensitizing concepts forces greater attention upon the micro-interactions and micro-geographies of interaction between two or more people in these semi-public or public spaces and reveals how these practices are themselves guided by rules and respective relationships. This further supports the theoretical sampling by guiding my attention to the physical outlay of businesses - how they are divided into different front and back stages, who and what kind of actors perform on the stage and who and what kind of audiences exist there, how strangers become familiar with the place and its people, how they turn these spaces into (more) 'private' spaces and practice (public) familiarity, and how these processes are fostered and negotiated by the owners and their staff's practices, how people observe each other and gain categorical knowledge of each other, and more generally, how civil inattention, audience role prominence, and civility towards diversity are practiced, what kind of relationships - fleeting, unbound or segmental - are typical for these (not necessary third) places.

\subsection{Sensitizing Concepts III: Community Building/ Senses of Belonging}

As outlined by means of Lofland and Goffman's work, the type of relationships and interactions define if a place is used as a public, private or mixed space, and thus help to reveal a business' respective potential for inclusion, integration, or community building. In that vein, the final set of sensitizing concepts to undergird my argument that the material qualities of a business along with the social practices of business people contribute to a socio-spatial setting that fosters feelings of belonging and community for their customers are the concepts of "community building" and "sense of belonging" themselves. These concepts are interrelated and I consider the latter as a vital component of the former.

For an ethnographic study of a shopping street and its businesses, the notion of neighborhood and its relationship to community and belonging are clearly crucial. Urban sociologists such as John Logan and Harvey Molotch (1987: 108) argue that neighborhood and community are not synonymous, but are implicitly connected with each other, defining neighborhood as "a shared interest in overlapping use values (identity, security, and so on) in a single area." Essentially, neighborhoods become meaningful to their locals (residents, but also people who work or oth- 
erwise spend a significant amount of time there), because of both the numerous social interactions in them, and the eventually shared 'values' and interests. Hence, neighborhoods - as physical or geographical sites - encompass not only a variety of interactions and exchanges that form a complex set of social and economic relations, but are also practiced and socially constructed themselves. Consequently, the problem that the physical boundaries of neighborhoods remain unclear seems to be inherent to the very nature of neighborhoods as socially constructed - in particular places at particular times, never specific or fixed. Yet, as the basic context and setting for everyday life, these socially constructed neighborhoods have real material consequences for the people who live and work in them (Martin 2003: 732).

The same ambiguity exists with the concept of community. Despite the fact that community has a longstanding prominent status and is a widely researched topic in urban studies, it remains unclear what community actually means:

[D] espite the legendary ambiguity of the concept of community, previous overviews largely agree on three basic components that have dominated definitions of community in the past: first, the presence of a shared territory; second, the presence of significant social ties; and third, the presence of meaningful social interaction (Kusenbach 2006: 280 f.).

Here Margarethe Kusenbach underlines the linkage between the two concepts of neighborhood and community but also their differentiation. As the third sensitizing or theoretical concept for this project, I thus argue that a local community needs a shared space and mutual relationships, but is first and foremost something that is practiced on the level of everyday life. This argument follows Kusenbach's critique that most community studies have prioritized the territorial and geographical notion of community - neighborhood, town, or city - and the "relational" which was concerned with the "quality of character of human relationship, without reference to location" (Gusfield 1975: xvi), over the third element, namely social interaction. But also Durkheim (1964) has already observed in the late $19^{\text {th }}$ century that "modern" society develops community around interests and skills more than around locality, whereas some of the newer concepts equally apply to territorial communities (neighborhoods) and to relational communities (e.g. professional, spiritual, et cetera).

Regardless if the definition of community is based on a shared geographical location, social networks, or interaction, community is not necessarily an all-inclusive concept. As such it is often used to muffle political opposition, and as a critique in the name of civility (Staeheli/ Mitchell 2006). Inasmuch as I claim that some of the businesses serve as the heart of the community for some residents - or essentially as a community center - community seems to be an appealing alter- 
native to public life (within a privately owned space). The concept of community promises to provide the pleasures of public sociability without the discomforts of the unfamiliar, hinting at the exclusionary dimensions of community (Kohn 2004: 193). By contrast, a full public implies challenging encounters and confrontation with random and different people, whereas community emphasizes commonality, smoothing over or even excluding difference. The reference to community can thus collapse the differentiation between the private and the public by incorporating appeals to private life, such as family, identity, security, but also forms of control (Staeheli/ Mitchell 2006: 978; Kohn 2004: 193). Civility, orderliness, responsibility, and conformity are at the center of community and community building. Hence, whenever I describe the practices of the chosen businesses and their employees' as contributing to community building, I am very aware of the exclusionary and disciplining nature of community that may decide over the quality and type of social practices and relationships in the businesses or the range of speech and allowed participation (Staeheli/ Mitchell 2006: 980).

However, businesses that act as the centers of their local communities do not always blend the public and private with the intention of increasing sales and the locale's overall profitability, even if the primary function of retailers and gastronomic facilities is consumption. In contrast to Lynn Staeheli and Don Mitchell's work (2006: $981 \mathrm{f}$.) on shopping malls as new community centers, I doubt that owners and employees of small retailers and gastronomic businesses use the notion of community as a disciplinary strategy in governance and regulation. As publicly accessible but private properties, owners and employees do decide what types of social practices are considered as 'civil' and thusly 'tolerated' and accepted, but sometimes customers practice community and occupy the businesses outside of the control of the employees. Further, the parameters for allowed practices in the businesses are less standardized than in shopping centers or chain stores and may change, depending, for instance, on the owner's personality, mood, daily turnover or customer mix. For more corporate businesses, the "communal" phenomena of consumption are widely recognized and part of daily business practices. Business owners and marketing experts actively attempt to increase the social link or "linking value" between customers and the respective product or service (Cova 1997: 297). Today different modes of consumption exist next to each other, such as traditional consumption, mass consumption, or individualized consumption (Cova 1997: 302). Combined with a changing landscape of communities, the many consumption modes as well as the many forms or modes of community (as social links), can be experienced by one person in the course of one day. Corporate rather than individually owned and smaller businesses often try to strategically capitalize on the assumed lack of local or social community outside of consumption places and 
thus "compensate" for this lack by developing and promoting a social link between their offered products and services and the customer, giving the customers (an illusion of) belonging to a certain place and consumer community (Cova 1997). The businesses thus become the linking places.

For the individually owned businesses along Karl-Marx-Straße, the enacted community at certain times of the day might also include the owners and employees themselves, whereby the norms of community may be changed and diluted. Nevertheless, the concept of community is inherently exclusionary, as it is based on the construction of difference. Communities are rooted in some element of commonality, which are recognized and accepted by their members, simultaneously reifying the differences are created - among the members, but first and foremost between members and non-members of a particular community. Hence, whenever community is generated or practiced, exclusionary processes and practices are likewise at work (Staeheli/ Mitchell 2006: 981). The small life worlds or communities of each sampled business also might be exclusionary towards certain individual customers or whole groups; not only on the basis of the social practices within the businesses, but also prior to entry, on the basis of the types of products and services sold, their lifestyle appeal, and price range.

Akin to the critique of the definition of community itself, the notion of a "sense of community" suffers from a similar lack of studies into the interactional or practical dimension - which then presents another avenue of analysis in my research. David McMillan and David Chavis (1986), for instance, propose four criteria for the definition of sense of community - membership, influence, the integration of needs, and shared emotional connection. The first element is membership, as the feeling of belonging or the perception that a sense of personal relatedness is shared. Membership is a feeling that one has invested parts of oneself in order to become a member and therefore has a right to belong. Here 'sense of belonging' is located within the concept of "sense of community" (McMillan/ Chavis 1986: 9). Certainly, this membership has boundaries - along lines of class, gender, ethnic background, language, or lifestyle symbols (e.g. clothes, languages, jewelry, food). As a common symbol system these define who is in or out of the perceived community ("we" vs. "them"). For instance, the locally spoken dialect in Neukölln (regardless of the ethnic background and further accents or dialects) serves to mark membership in the neighborhood and knowledge about its history in most businesses. These boundaries also serve to delineate whom to trust, thereby establishing the basis and 
structures for emotional safety, as well as a sense of belonging, ${ }^{92}$ leading to personal investments which provide a feeling that one has earned a place in the group.

The second element, influence, is a sense of mattering or of making a difference to a group and vice versa. These two forces - a push for conformity by the group and a push for cohesion by the individual - work in concert, generally balancing the conflicts around group cohesiveness and conformity. However, conformity does not necessarily mean a loss of personal choice for the individual, if the communities in question appreciate individual difference. Conformity derives out of a feeling that a group member either can directly or indirectly exert some control over the community (McMillan/ Chavis 1986: 10).

The third element is a feeling that members' needs will be integrated or met by the resources accumulated through group membership. In order to maintain the sense of togetherness, the individual-group association must be rewarding for its members. The possible reinforcements that bind people together into a close community can be, for instance, the status of being a member or shared values.

Shared emotional connection as the commitment and belief that members share a common history, place, time together, and similar experiences (and will continue to do so in the future) rounds out the fourth element. On the basis of the so-called contact hypothesis, which states that "the more people interact, the more likely they are to become close" (Allport 1954), a shared connection is developed by the quality of interaction (the more positive the experiences, the greater the bond), the closure to events (group cohesiveness is curbed if interactions are ambiguous), shared events (the more, the better), constant investment (the greater the investment, the more important is the community's history and current status are to members), honor/ humiliation (making community membership attractive or repulsive to the individual), spiritual bonds (prevalent in religious groups or cults but to some degree in all communities) (McMillan/ Chavis 1986: $13 \mathrm{f}$.). The concept of shared emotional connection functions similarly to Tönnies' (1957) notion of Gemeinschaft as a social unity based on locale. However, even if Gemeinschaft is conceptualized as the village-type or the small-town community, shared emotional connections do not require a small-scale local community. McMillan and Chavis (1986: 14 following Kasarda/ Janowitz 1974: 388) argue that increased population size and density do not significantly weaken local community sentiments, and as such, that

92 As per McMillan and Chavis (1986: 10), "the sense of belonging and identification involves the feeling, belief, and expectation that one fits in the group and bas a place there, a feeling of acceptance by the group, and a willingness to sacrifice for the group. The role of identification must be emphasized here. It may be represented in the reciprocal statements "It is my group" and "I am part of the group." I use this as a first definition for "sense of belonging." 
communities are not necessarily bounded by location. According to them, shared emotional connection seems to be the definitive element for "true community." 93

In short, McMillan and Chavis propose that a "sense of community" is a feeling of belonging, a feeling that members matter to one another and to the group, and a shared faith that members' needs will be met through their commitment to be together (McMillan/ Chavis 1986: 9; see also McMillan 1976). Despite its operational character, this definition still focuses primarily on the perceptional and emotional level and leaves out the interactional element of community. I argue that community is something that is practiced on an everyday level, whereas a perception or sense of community derives out of interaction with other (potential) community members.

As we can see, the dominant definitions for both community and sense of community use either territorial or relational descriptors. Whereas research emphasizing the territorial (especially within social network theory) has long diagnosed and bemoaned the decline or loss of community (cf. Putnam 1995; 2000), the research on relational aspects has begun to understand community as transformed, liberated, or even saved (cf. Wellman 1979; Wellman/ Leighton 1979), arguing for a "radical despatialization and individualization of the concept" (Kusenbach 2006: 281). In between these two research streams that either overemphasizes the spatial or (individual) social ties, I use "community" only as a sensitizing concept and argue for the spatial reality of social ties in face-to-face interactions.

In the empirical part of this study, the definition of community has been left up to the interview partners and not the interviewer (myself). Community ("Gemeinschaft") is as a very strong or even archaic term in German, denoting very strong and tight ties, and is therefore rarely used in everyday language. But if conceptualized as something that is practiced over the course of daily life, the respective community building practices and utterances can be observed empirically. Following McMillan and Chavis' definition of sense of community - highlighting the individual's subjective sense of rather than a fixed list of characteristics for community -, these are practices and utterances around membership, belonging, mutual mattering, and trust that need to be fulfilled in the community. I assume that the doings and sayings do not always match, for instance, that more or less customers belong to a business' social world (Honer 2011; Hitzler/ Honer 1991) than the store owner mentions, or that the strength and spectrum of membership in local communities is differently framed than observed. Whenever community building practices or practices that foster a sense of belonging are observed, it remains unclear what

93 McMillan/ Chavis (1986: $15 \mathrm{ff}$.) further argue that there is a high dynamic within and among these elements of sense of community, yet with the core element of shared emotional connections. 
sense of community means to its members. However, the focus of this study lies on the store owners and salespeople's practices that create the social spaces and foster senses of home and belonging and consequently feelings of community and not on the meaning of these community memberships for the customers themselves - even if this would be highly interesting and socially significant.

Hence, community is conceptualized as social conduct as "communal interaction." According to Lofland (2003: 939 f.), if one considers the city as the interactional context for community building, primary relationships are still as plentiful in urban as in any other settings. Despite the concerns of both dominant research streams, secondary relationships do not replace family and neighborhood ties; rather, they supplement them. If primary and secondary relationships exist next to each other in the city and beyond (due to new means of communication and transportation) the question remains where or in what environment and between whom they still are practiced in situ.

I argue that within the city as an interactional context for community, Karl-MarxStraße represents the contact zone and the local businesses the concrete contact spaces for face-to-face interaction that enacts some kind of (time-/space-bounded) community. More precisely, much of this face-to-face interaction that builds community in the course of routine life takes place in the most used and frequented local spaces and places, namely the local shopping streets and their amenities. Whereas residential and work places ${ }^{94}$ encompass already existing community ties among already familiar (but preselected) people, in these parochial, semi-public, or public settings, unfamiliar or only partially known individuals are encountered. Through social interactions in these spaces, membership in some kind of community might then develop. Although the concepts of community or a sense of community remain vague, deploying McMillan and Chavis' operational definition, and the open process of letting interview partners and research subjects define community (even if the term is not used at all) as part of their "home," as sensitizing concepts, draws attention to the potential benefits or positive outcomes of the store owners' practices on Karl-Marx-Straße.

Nevertheless, as noted earlier, inclusion in a community implies exclusion as well. Membership in a community might also carry negative consequences in the form of social control or the imposition of a set of values and rules that prevents integration into wider society. For the businesses on Karl-Marx-Straße, the creation of a social life world in one place might be geared to the exclusive social circle of local residents, to the exclusion of others, e.g. along class, gender, ethnicity, and

94 These are the first and second places in Oldenburg's interpretation (Oldenburg/Brissett 1982). 
lifestyle lines. Using community only as a sensitizing concept (versus as a normative value) further allows for an awareness of the negative consequences of the business people's practices.

Weaving together Oldenburg's list of third place attributes, Jacobs' concept of public characters, and Lofland's conceptual framework of private, public, and parochial spaces and the respective (Goffmanian) urban relationships and behavioral forms, I argue for the inclusion of the everyday practices in urban retail and gastronomic businesses in our understanding of community creation and maintenance. As everyday places, they reveal a high proportion of non-institutional and low-threshold interactions between residents with diverse socio-economic and ethnic backgrounds. Treated as socially insignificant for a long time in urban sociology, I hypothesize that these fleeting, segmental, and unbound interactions and relationships in public and semi-public spaces, might nonetheless add up to (a sense of practiced) community and feelings of belonging, no matter how ambivalent the outcomes.

To conclude, I conceptualize community and belonging as something that is practiced on a routine daily level and as a set of interactive practices that characterizes a neighborhood as a type of parochial territory (Lofland 1973; 1989; Kusenbach 2006: 282). Even in their most superficial and ephemeral form, physical and verbal interactions in local businesses form a crucial ingredient in the development of community and a sense of belonging for some customers and staff. The in-business social interaction (as a set of social practices) thus represents the smallest building block of any type of community - the social component. It is therefore essential to research these interactional spaces in which community is practiced in a nuanced way, as in this case presented here, where the businesses themselves represent a significant micro-sociological community place - the spatial component of community (building) on Karl-Marx-Straße.

\subsection{Summary: Use of Sensitizing Concepts for the Sampling rocess}

A grounded theory is generated by initial themes that then merge with themes developed from the data during analysis, capturing the essence of experiences derived from different contexts and situations. Consequently, theory generation requires sensitizing concepts but no research hypotheses. In line with its inductive nature, grounded theory as qualitative research instead involves the researcher's attempts to detect, understand, and interpret the emerging themes in the research process. Sensitizing concepts thereby help to discover, organize and understand 
experiences and situations (Bowen 2006: 2 f.). The three sets of sensitizing concepts draw attention to important features of social interaction and of the respective contact sites, and thus lay the foundation for an analysis of research data, but also provide guidelines for the empirical research in these specific settings.

For Karl-Marx-Straße, the three sets of sensitizing concepts are used as interpretive devices and as a starting point for the ethnographic study of a select number of businesses that exemplify the wider commercial structure and its respective local social life. Even if the concepts of third place and public characters, public behavior, and community building represent only background ideas that inform the overall research problem and process, they may "deepen perception, they provide starting points for building analysis, not ending points for evading it. We may use sensitizing concepts only as points of departure from which to study the data" (Charmaz 2003: 259 f.).

Accordingly, these three sets also form the conceptual framework, serving as an impetus for the later formulation of theory, including the basic argument of this book, that business people's everyday practices in the businesses on Karl-MarxStraße foster interactions that might lead to a sense of belonging or community for some of the customers.

Open Access This chapter is licensed under the terms of the Creative Commons Attribution 4.0 International License (http://creativecommons.org/licenses/by/4.0/), which permits use, sharing, adaptation, distribution and reproduction in any medium or format, as long as you give appropriate credit to the original author(s) and the source, provide a link to the Creative Commons license and indicate if changes were made.

The images or other third party material in this chapter are included in the chapter's Creative Commons license, unless indicated otherwise in a credit line to the material. If material is not included in the chapter's Creative Commons license and your intended use is not permitted by statutory regulation or exceeds the permitted use, you will need to obtain permission directly from the copyright holder.

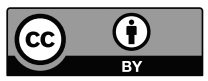

